\title{
LA DENOMINADA TROCHA FRONTERIZA EN LA FRONTERA ENTRE COSTA RiCA Y NICARAGUA: BREVE ANÁLISIS DESDE LA PERSPECTIVA INTERNACIONAL
}

\author{
The so-called parallel trail along the boundary between Costa Rica and Nicaragua: \\ brief reflections from an international perspective
}

Nicolás Boeglin-Naumovic

Resumen: Enel siguiente artículo se presenta un análisis desde la perspectiva internacional de las implicaciones que puede tener para Costa Rica la construcción, iniciada en 2011, de la denominada "trocha" paralela a la frontera con Nicaragua, una ruta que incluye en su mayor trayecto el río San Juan, río fronterizo entre ambos países. El objetivo consiste en situar los alcances de esta controversia a la luzdel derecho internacional tras la demanda interpuesta por Nicaragua ante la Corte Internacional de Justicia de la Haya en marzo de 2011.

Palabras clave: fronteras internacionales, conflictos internacionales, derecho internacional.

Abstract: The following article analyses from an international legal perspective the implications for Costa Rica of building a road parallel to the boundary line with Nicaragua, initiated in 2011, that includes the San Juan River shared between the two countries. The objective is placing the scope of this dispute in the light of international law after a request of Nicaragua before the International Court of Justice in the Hague, in March 2011.

Keywords: international borders, international conflicts, international law.

\footnotetext{
Nicolás Boeglin-Naumovic, doctor en Derecho por la Universidad de Paris II. Profesor de Derecho Internacional Público en la Facultad de Derecho de la Universidad de Costa Rica y en la maestría en Diplomacia del Instituto del Servicio Exterior Manuel María Peralta del Ministerio de Relaciones Exteriores —Convenio ISE/UCRProfesor de Derecho Internacional Ambiental en la Maestría de Derecho Ambiental —Cátedra UNITAR — de la Facultad de Derecho de la Universidad de Costa Rica. Temas de especialización: fronteras internacionales, cursos de agua internacionales, acuíferos transfronterizos, derecho ambiental internacional, cooperación transfronteriza. Correo electrónico: nboeglin@gmail.com.
}

Enviado a dictamen: 14 de nero de 2013. Aprobación: 15 de marzo de 2013.

Revisiones: 1 . 


\section{Introducción}

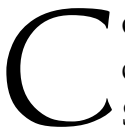

osta Rica y Nicaragua comparten la mayor cuenca transfronteriza de América Central. Se trata de la cuenca del río San Juan, de unos 38500 kilómetros cuadrados de extensión, de los cuales 24500 (64\%) pertenecen a Nicaragua y 14 $000(36 \%)$ a Costa Rica (ver mapa 1$)$.

En esta cuenca, el río San Juan constituye la desembocadura común de los distintos afluentes que se encuentran en ambos Estados. Aunque la contribución en caudal es muy desigual, son los ríos costarricenses Río Frío, San Carlos y Sarapiquí los que aportan el mayor caudal al San Juan. El cauce de este río constituye además la frontera entre ambos países, según lo establece el tratado de límites Cañas-Jerez suscrito en 1858. A diferencia de muchas otras fronteras en el mundo, los términos de este tratado no se definieron exclusivamente en las capitales de Costa Rica y Nicaragua, sino también en Washington y Londres - a mediados del siglo XIX, las dos potencias del momento, Gran Bretaña y Estados Unidos, se disputaban el control sobre la futura vía interoceánica y realizaron las gestiones diplomáticas necesarias para que el régimen de la frontera entre Costa Rica y Nicaragua se ajustara a sus intereses-. En otras palabras, la frontera entre Costa Rica y Nicaragua se definió en función de un proyecto de ruta interoceánica con base en los intereses de dos grandes potencias extrarregionales y no en los intereses de los Estados ribereños del río San Juan. Al no haberse materializado nunca este proyecto de vía interoceánica pese a los esfuerzos realizados desde 1858, el San Juan se ha convertido en un factor de tensión y de confrontación entre los dos países.

En los últimos decenios podemos destacar varias fases. El período 1990-1998 supuso una fase de distensión durante la cual se materializó el Proyecto Pro Cuenca Río San Juan, programa auspiciado por Costa Rica y Nicaragua con el apoyo de la Organización de los Estados Americanos (OEA) en 1996, y en esta fase culminó la campaña de densificación de mojones (1994-1998) a cargo de los institutos geográficos de ambos países. A ésta siguió una fase de confrontación en relación con el río San Juan que explica que en menos de siete años (2005-2011) ambos Estados hayan recurrido a la Corte Internacional de Justicia de La Haya (CIJ) en tres ocasiones: a) demanda de Costa Rica por derechos de navegación y derechos conexos en el San Juan, resuelta por la CIJ en julio de 2009; b) demanda de Costa Rica por el dragado del río San Juan realizado por Nicaragua, presentada en noviembre de 2010; y c) demanda de Nicaragua por la construcción de una ruta paralela al río San Juan en diciembre de 2011. Se trata de una situación inaudita y sin precedentes en los anales del tribunal de justicia internacional en La Haya que proporciona una idea del clima existente entre ambos países ribereños del San Juan.

No obstante, estas recientes controversias en torno al río San Juan no debieran ser consideradas como parte de los conflictos por el agua que sacuden un sinnúmero de fronteras en el mundo - más conocidos como parte de la "hidropolítica", traducción del concepto inglés hydropolitics-y que se observan, por ejemplo: en las tensiones recurrentes entre Siria e Irak en relación con los usos que hace Turquía de sus ríos; o en las tensiones entre Egipto y los estados situados aguas arriba de la cuenca del Nilo; o en el desvío de caudal al que ha procedido Estados Unidos en el río Grande, tensando sus relaciones con México. En el caso que nos ocupa, ambos países ribereños del San Juan lidian desde el siglo XIX con un régimen de su frontera común concebido para un proyecto que nunca vio el día - la vía interoceánica-; uno de ellos, Nicaragua, mantiene la idea de construir algún día una vía interoceánica que pase por su territorio y para ello ha intentado extender su control sobre la parte terminal del San Juan.

El último episodio de esta larga serie de tensiones originadas por el San Juan en los últimos años lo constituye la construcción, iniciada por Costa Rica en marzo de 2011, de una ruta paralela al río San Juan y a un sector de la frontera terrestre entre ambos Estados. Lo que se denomina popularmente como "trocha fronteriza" ha sido objeto de cuestionamientos desde la perspectiva interna en Costa Rica debido a la descoordinación, improvisación y probables actos 
de corrupción investigados desde agosto de 2012 por una comisión de la Asamblea Legislativa de Costa Rica. Sin embargo, desde la perspectiva internacional este proyecto también tiene serias implicaciones para Costa Rica. El objetivo de este artículo es situar los alcances de esta nueva controversia surgida entre los dos países a la luz de las reglas que imperan en el derecho internacional. En este sentido, nos limitaremos únicamente a la posición oficial de éstos, o de sus entidades públicas, dejando a un lado las posiciones de grupos sociales, de partidos políticos, o de entidades o grupos que no califican como entidades públicas estatales - organizaciones de la sociedad civil, sectores económicos o poblaciones fronterizas, por ejemplo-. Ello con el fin de entender mejor los desafíos que este nuevo episodio en sus relaciones bilaterales significa para ambos Estados. Para ello, en una primera parte nos abocaremos a describir la realidad geográfica del río San Juan, para luego interesarnos por las condiciones que imperaron para tomar la decisión de realizar dicho proyecto de ruta paralela a la frontera. Posteriormente, intentaremos conocer cuál es la intención que persigue Nicaragua al haber presentado la demanda ante la CIJ. En una cuarta parte detallaremos algunas de las dificultades que le genera a Costa Rica esta demanda, para finalmente apuntar hacia lo que posiblemente constituye una primera experiencia de este tipo realizada por un Estado en América Latina.

\section{Breve descripción del río San Juan}

El río San Juan es un río fronterizo entre Costa Rica y Nicaragua, el cual presenta unas características particulares que hacen de su gestión un ejercicio mucho más delicado que para otros ríos fronterizos.

\section{Características geográficas}

En su primer sector, desde su salida del Gran Lago, ambas márgenes del San Juan están sometidas a un solo Estado, Nicaragua. Luego, a partir de un punto conocido como punta la Triela en Nicaragua, y San Isidro en Costa Rica, sus dos márgenes están sometidas a la jurisdicción de cada uno de los dos Estados. Un detalle de importancia sobre el espacio fluvial en sí es que Nicaragua es el Estado que ejerce el "dominio y sumo imperio" de manera exclusiva hasta San Juan del Norte; ello en virtud de la técnica de delimitación acordada en 1858, técnica de límite al margen del río usada también para ríos internacionales como el Shatt-el-arab -entre Irán e Irak-, el Amour -entre Rusia y China-, el Tinto y el Motagua —entre Guatemala y Honduras-, el Senegal —entre Senegal y Mauritania - el San Pedro y el Tendo -entre Senegal y Gambia - o el río Odong —entre Malasia e Indonesia - en vez de la técnica más equitativa de la línea mediana o thalweg — canal navegable más profundo-, utilizada, por ejemplo, para delimitar el río Sixaola en el tratado Echandi-Fernández de 1941 - entre Costa Rica y Panamá-. En la parte terminal del río San Juan, por efecto de un proceso natural, se da una situación muy particular:

a. el caudal principal del San Juan desemboca en un río propiamente nacional de Costa Rica, el río Colorado, del que dependen en gran medida los canales de Tortuguero y los humedales de la zona norte de Costa Rica;

b. mientras que una parte mínima del caudal del San Juan desemboca en la bahía de San Juan del Norte (ver mapa 2).

\section{Una segmentación compleja}

La situación geográfica del río San Juan antes señalada conlleva para ambos estados ribereños un grado de dificultad mucho mayor que el que enfrentan otros Estados en la gestión de ríos internacionales. Con respecto a esta última referencia cabe indicar que, en la reciente controversia en La Haya en relación con los derechos de navegación en el río San Juan entre Costa Rica y Nicaragua, la calificación del San Juan como río nacional o como río internacional quedó irresuelta por parte de la CIJ pese a los intensos esfuerzos desplegados por ambas partes en su contienda entre 2005 y 2009: mientras Costa Rica defendió su carácter internacional, Nicaragua mantuvo en sus argumentos la idea de un 
río nacional. En su decisión del 13 de julio de 2009, la CIJ afirma que:

[...] no cree tampoco, en consecuencia, deber decidir sobre el punto de saber si el San Juan entra en la categoría de los "ríos internacionales" — tal como lo sostiene Costa Rica - o si constituye un río nacional que comporta un elemento internacional según la tesis de Nicaragua (párrafo 34, traducción libre del autor).

Desde el punto de vista de la nomenclatura más reciente del derecho internacional público, la cual considera ya no el cauce de los ríos internacionales, sino el sistema de aguas que los conforman, el río San Juan puede ser considerado como un curso de agua internacional; no se trata de una afirmación gratuita, sino que se desprende de la definición dada en 1997, en el marco de las Naciones Unidas, por la Convención sobre el derecho de los usos de los cursos de agua internacionales para fines distintos de la navegación, firmada en Nueva York en diciembre de 1997. Leemos en efecto en ella (art. 2) que la noción de "curso de agua" se entiende como: "un sistema de aguas de superficie y subterráneas que, en virtud de su relación física, constituyen un conjunto unitario y normalmente fluyen a una desembocadura común."

El texto prosigue indicando que por "curso de agua internacional" se entenderá: "un curso de agua algunas de cuyas partes se encuentran en Estados distintos." El río San Juan se ajusta plenamente a la definición dada por este instrumento internacional de 1997, la cual es indiferente a la técnica de delimitación acordada entre los estados ribereños - sea ésta thalweg, línea media, margen único, doble margen u otra técnica de delimitación fluvial一.

\section{La decisión de construir una ruta paralela al río San Juan}

La ruta paralela al San Juan, iniciada en 2011, es considerada oficialmente como una respuesta de Costa Rica, no tanto a la operación de dragado realizada en octubre de 2010 por Nicaragua, sino a una situación no prevista: la ocupación ilegal por parte de Nicaragua de un territorio en una remota zona fronteriza de Costa Rica. Para entender la pretendida relación entre ambos casos, es menester devolver brevemente al lector al dragado realizado por Nicaragua y a las implicaciones internacionales que esto tuvo para Costa Rica, de tal manera que este último país se vio obligado a llevar el tema ante la justicia internacional.

\section{El dragado del río San Juan por parte de Nicaragua}

El dragado iniciado por Nicaragua en la parte terminal del San Juan en octubre de 2010 dio lugar a una demanda formal de Costa Rica ante la CIJ presentada en noviembre de 2010, la cual incluía una solicitud de medidas provisionales. Esta operación de dragado se realizó con la anuencia de las autoridades de Costa Rica, para la sorpresa de muchos y pese a las advertencias de varios académicos de Costa Rica, quienes alertaron a las autoridades de los daños que pudiera causar esta operación sin los estudios de impacto pertinentes (Astorga, 2010a; Astorga, 2010b; Boeglin, 2010), en particular, el Estudio de Impacto Ambiental Transfronterizo que recogen tanto tratados internacionales ambientales de los que son parte ambos estados, como sus propias legislaciones internas. Lo que no se preveía era que Nicaragua construyera un caño artificial en territorio costarricense y que, una vez detectada su presencia en suelo costarricense, alegara, entre otros argumentos, basarse en los mapas de Google Map para posicionar su proyecto. Al percatarse de su error, la empresa Google procedió a rectificar sus mapas en noviembre de 2010, pero el Gobierno de Nicaragua mantuvo su posición (Mata, 2010; Walker, 2010). Posiblemente este grave conflicto diplomático entre Costa Rica y Nicaragua sea el primero en la historia causado por un error de los mapas de Google.

La polémica fue llevada ante la Organización de Estados Americanos (OEA) entre octubre y noviembre de 2010 sin mayores resultados, hasta que finalmente Costa Rica procedió a entablar una demanda contra Nicaragua ante la CIJ a finales de noviembre de 2010 mediante la cual solicitaba urgentemente a la Corte la adopción de medidas provisionales. El 8 de marzo de 
2011, los 17 jueces de la CIJ exigieron por unanimidad a ambas partes:

1. retirarse de la zona en conflicto (Isla Portillos) incluyendo el "caño" (o canal denominado "caño Pastora" o "caño Google");

2. no tomar acciones que puedan agravar, extender o dificultar la situación y;

3. informar a la CIJ (ambas partes) sobre el seguimiento a estas medidas ordenadas.

Adicionalmente, en relación con el punto uno, por una votación de 13 contra cuatro, la CIJ permite a Costa Rica penetrar en lo que se denomina la "zona en conflicto", pero únicamente con personal civil técnico en materia ambiental para evitar que un daño irreversible se esté cometiendo - being caused reza el texto oficial- en la zona. También consta que debería consultar con la Secretaría de la Convención Ramsar, informar previamente a Nicaragua sobre sus actividades y hacer lo posible para buscar soluciones comunes con Nicaragua.

Los tres primeros puntos de esta "providencia" según el término oficial- del 8 de marzo se inscriben en la más clásica tradición de medidas ordenadas en conflictos fronterizos: el nerviosismo de los mandos militares a menudo provoca incidentes graves, y alejarlos de una zona en litigio es un mecanismo de prevención. De manera accesoria, la CIJ establece un sistema de evaluación en materia ambiental en la zona en conflicto cuya formulación evidencia que estamos ante una solución de compromiso entre los 17 jueces: establece un modus operandi que no resulta muy claro al involucrar, además de a las dos partes, a una entidad internacional. Las condiciones en las que los técnicos de Costa Rica y de RAMSAR realizaron la visita a inicios del mes de abril de 2011, demuestran la necesidad de que ambos países acuerden un protocolo para estas evaluaciones, en vez de prestarse a interpretaciones algo antojadizas sobre las competencias de cada Estado y el papel de RAMSAR.

El caso del dragado iniciado por Nicaragua en octubre de 2010 podía ser presentado de dos maneras ante los jueces en La Haya: como un proyecto que genera un daño ambiental transfronterizo y que adicionalmente se agrava con una ocupación ilegal del territorio nacional; o como una grave violación a la soberanía territorial que además causa un daño ambiental. La CIJ - la cual desde noviembre de 2010 había denominado oficialmente este caso, sin aún conocer los descargos de Nicaragua, como "ciertas actividades de Nicaragua en la región fronteriza"parece haberse inclinado por la segunda lectura, dado que no ordena suspender la actividad que provoca el daño - el dragado-, ni considera que las pruebas aportadas por Costa Rica -documentos técnicos, informes RAMSAR, tomas satelitales- establezcan la irreversibilidad del daño ambiental. Considera que, habiéndose concluido el canal Pastora, Nicaragua no puede proceder a más trabajos — validando así las afirmaciones de Nicaragua ante el retiro de sus tropas en enero de 2010- . Tampoco exige medidas inmediatas para mitigar los efectos que pueda producir el aumento del caudal de las aguas que ahora fluyen por el "caño" en la geomorfología de la zona y en los ecosistemas aledaños a la Laguna de los Portillos.

Sobra decir que, ante las inconsistencias de Costa Rica en relación con el daño ambiental y su caracterización, y ante las hábiles maniobras de los asesores de Nicaragua, estas medidas provisionales - teóricamente urgentes - fueron dictaminadas para su cumplimiento en el mayor plazo jamás registrado en la historia de la $\mathrm{CIJ}$ - que puede ir de unos días a unos meses según su convencimiento de la supuesta urgencia-. La línea defendida por Nicaragua consistió en intentar convencer a los jueces de La Haya de que el problema debía tratarse como una disputa clásica en materia territorial en razón de la indeterminación de la frontera en esta remota e inhóspita zona fronteriza. Esta línea argumentativa pareciera haber logrado pasar este primer ejercicio: contó para ello con la habilidad de Nicaragua para explotar algunos errores cometidos por Costa Rica. Uno de estos errores fue el haber promovido en la OEA una resolución en la que se solicitaba decretar una zona de repliegue: posiblemente sea la primera vez en la historia en la que un Estado que alega ser ocupado 
de manera ilegal, mapa en mano, solicita retirarse de su propio territorio.

$\mathrm{Al}$ revisar la decisión de la CIJ, resulta evidente su intención de calmar los ánimos entre ambos Estados y de permitirles un espacio para reconstruir sus deterioradas relaciones. En varias partes del texto invita explícitamente a éstos a buscar soluciones consensuadas y a trabajar conjuntamente: una clara señal de que, después de la crisis, se presentan oportunidades que hay que saber aprovechar para restaurar progresiva y paulatinamente mecanismos de diálogo y concertación. Pese a este llamado, en cada lado del río San Juan se oyeron, por parte de las más altas autoridades, declaraciones oficiales que celebraban la victoria conseguida en La Haya: mientras Costa Rica celebró que Nicaragua tuviese que abandonar Isla Portillos declarado territorio en disputa- y lo que su canciller René Castro denominó la "custodia ambiental" en Isla Portillos, Nicaragua celebró que no se le impidiera continuar con la operación del dragado y que Costa Rica fuese obligada a retirarse también de Isla Portillos. Por otra parte, afirmaciones extrañamente inoportunas del ministro de Seguridad de Costa Rica al día siguiente de leerse la sentencia en La Haya, anunciaron que Costa Rica iniciaría una operación de desminado por "sospechas" de que las autoridades nicaragüenses habían colocado este tipo de artefactos en la zona. No son éstas las señales que La Haya esperaba, sino otras dirigidas a reinstaurar progresivamente un clima más propicio tendiente a normalizar poco a poco el curso de las aguas entre ambos países. La mesura y la prudencia debieron prevalecer en los días siguientes al 8 de marzo de 2011, pero al parecer altas autoridades de ambos Estados se prestaron a un ejercicio dirigido a tensar más aún el clima de desconfianza entre los dos países, aunque uno contribuyó más que otro. La invitación del presidente de Nicaragua a la presidenta de Costa Rica para que juntos escucharan la lectura del fallo el 8 de marzo en algún punto en la frontera, fue objeto de rechazo por parte de Costa Rica: este tipo de rechazos, y muchos otros que siguieron posteriormente de Nicaragua hacia Costa Rica, podrá ser útilmente aprovechado en algún momento por Nicaragua ante un tercero como la CIJ.
A modo de ejemplo, podemos recordar otro doloroso caso entre dos naciones latinoamericanas, Argentina y Uruguay, que celebraron una cumbre presidencial a escasos ocho días del fallo de la CIJ del 20 de abril de 2010 en relación con las plantas de celulosa en el Río de la Plata. Se trata de gestos simbólicos y de señales políticas que buscan redimensionar las cosas después de una prolongada y desgastante guerra verbal entre dos contendientes. Nada de esto ocurrió después del 8 de marzo de 2011 entre Costa Rica y Nicaragua. A menos de un mes de esta decisión, el 12 de abril de 2011, ambos países decidieron reunirse en la localidad fronteriza de Peñas Blancas, con presencia de los cancilleres de México y Guatemala como observadores internacionales. Ambos pudieron ver cómo se procedió a retirar la malla para colocar la mesa de trabajo, de manera que ni la delegación oficial de Costa Rica ni la de Nicaragua debían cruzar la línea fronteriza. Sin lugar a dudas, éste y otros detalles ofrecen una idea de la desconfianza y del clima de extrema tensión que ambos estados parecieran complacerse en cultivar (Alfaro, 2011).

\section{La ruta paralela a la frontera como respuesta al dragado}

Retornando en el tiempo, el manejo de la crisis suscitada con Nicaragua por parte de las autoridades de Costa Rica a partir de octubre de 2010 no fue el mejor, y asistimos a una verdadera escalada en el conflicto. Un analista costarricense no dudó en escribir que:

Uno de los elementos que marcó fue la definición de éste como un asunto de seguridad, en el cual el entonces Ministro de Seguridad de Costa Rica, José María Tijerino, mantuvo un acentuado protagonismo y frente al cual la Cancillería costarricense más bien se percibió como en un segundo plano, sobre todo antes de ventilar el caso ante la OEA (Sandoval García, 2012: 181).

La escalada de la confrontación verbal y diplomática llegó a tal punto que, a modo de respuesta ante la denominada "agresión" o "invasión" sufrida por Costa 
Rica, sus autoridades aprobaron un decreto ejecutivo de emergencia, publicado el 7 de marzo de 2011 — un día antes de la lectura de la decisión de la CIJ—, el cual, entre otros considerandos, indica que:

IV.-Que con la invasión militar y ocupación realizada por Nicaragua en Costa Rica desde el mes de octubre del 2010, tropas nicaragüenses ocupan una parte del territorio de Costa Rica, en clara violación a la soberanía, integridad territorial y dignidad nacional. V.- Que lo anterior ha generado una constante violación a los espacios terrestres, aéreos y marítimos de Costa Rica, afectando no sólo la soberanía nacional, sino que también ha generado una grave devastación ambiental al destruirse delicadas zonas de humedales nacionales, debidamente registradas y reconocidas a nivel internacional. VII.- Que producto de las acciones ejecutadas por el ejército de Nicaragua y por el Gobierno de ese país, varias comunidades costarricenses a lo largo de la zona fronteriza, y las instituciones del Gobierno, han visto alteradas sus condiciones normales de funcionamiento, quedando algunas, incluso, aisladas, sin contar con las vías que les permitan el acceso a los servicios básicos de salud, alimentación, educación, entre otros, y colocadas en evidentes condiciones de vulnerabilidad. VIII.-Que la zona que se ha visto afectada por las acciones del Gobierno y el Ejército nicaragüense, se encuentra, además amenazada por constantes fenómenos naturales, que producen, entre otras afectaciones, inundaciones.

Este decreto ejecutivo y sus considerandos sirven de base legal para iniciar la construcción o mejoría de caminos vecinales para acceder al río San Juan desde territorio costarricense. No aparece explicitada la construcción de una ruta paralela al río San Juan de 160 kilómetros de largo como tal. Sin que a la fecha se tenga claridad sobre quiénes ordenaron su construcción dentro del estado costarricense, este mismo decreto sirvió de sustento jurídico para la construcción de una ruta paralela al río San Juan de 160 kilómetros de largo. En un artículo titulado "Se mantiene interrogante de quién ordenó construir la trocha fronteriza" de agosto de 2012, se lee en efecto que:

En una situación como la descrita se entiende que en un primer momento se ordenara al MOPT y el CONAVI reparar y habilitar las vías de acceso a la zona del conflicto, para movilizar a la Fuerza Pública y evacuar a la población de ser necesario, o bien, construir obstáculos en los ríos para impedir la incursión de embarcaciones, como se pensó en un principio. Pero, hacer una carretera nueva a lo largo de la frontera como se decidió después que salió el decreto de emergencia es otra cosa, según ese razonamiento (Araya, 2012).

En una aclaración reciente ante los medios de prensa realizada en enero de 2013, el mismo exministro de Seguridad de Costa Rica, José María Tijerino, es enfático al precisar:

[...] por razones de logística policial solicité al ministro del MOPT interponer sus buenos oficios para la reparación de los caminos que conducen a Delta Costa Rica y Boca del Río Sarapiquí, en el cantón de Sarapiquí; a Puerto Lindo, en el cantón de Pococí, y a la población de La Trocha, en el cantón de Los Chiles (Tijerino, 2013).

Mientras prosiguen las investigaciones por parte de una comisión de la Asamblea Legislativa, podemos decir que estamos en presencia de un vasto proyecto declarado como prioritario por la actual administración de la presidenta Laura Chinchilla, pero sin que, a la fecha, se tenga claridad sobre quién o quiénes ordenaron su construcción. Ello, en nuestra modesta opinión, no deja de sorprender profundamente y puede dejar perplejo a cualquier observador.

El decreto de emergencia adoptado en marzo de 2011 fue objeto de varios recursos legales interpuestos ante la Sala Constitucional de la Corte Suprema de Justicia de Costa Rica. Uno de ellos invoca la desproporción existente entre la causa que origina la controversia, ubicada en una pequeña y remota zona - Isla 
Portillos - cerca de la frontera con Nicaragua, y la respuesta de este decreto de emergencia, que pretende tutelar legalmente una extensa área que comprende los seis cantones fronterizos. En el último recurso de inconstitucionalidad contra este decreto, el cual fue rechazado ad portas por la Sala Constitucional, el recurrente alegaba que:

[...] el Decreto se fundamenta en el hecho de que existe una invasión militar de parte del gobierno de Nicaragua, lo cual cuestiona porque no hay una declaratoria de guerra, no se han roto las relaciones comerciales ni se ha cerrado la frontera. Refiere que el Decreto declara la emergencia en los seis cantones de la zona: La Cruz, Upala, Los Chiles, Sarapiquí, San Carlos y Pococí; cuando el conflicto fronterizo se reduce a un área de 3 kilómetros cuadrados, en el Caribe noroeste, cantón de Pococí, Isla Portillo-Isla Calero, por lo que estima que no hay justificación para crear un régimen de excepción en los 6 cantones. El Decreto señala que varios poblados se han quedado aislados y sin servicios básicos de salud, alimentación y educación, entre otros. Sin embargo, no explica la relación entre el aislamiento de los pueblos, la invasión en el sector Caribe noroeste y los problemas de alimentación o educación. Se indica que existen riesgos en la zona por inundaciones y fenómenos naturales, pero no se aprecia la relación entre riesgos de inundaciones y fenómenos naturales y el conflicto por la invasión al territorio. Como segundo aspecto, aduce que con la construcción de la trocha o carretera fronteriza, se han producido afectaciones al medio ambiente, a los principios de proporcionalidad y razonabilidad, irreductibilidad del bosque y precautorio (República de Costa Rica, Sala Constitucional de la Corte Suprema de Justicia, 2012).

Notemos que la Sala indicó en su rechazo - el cual contó con los votos del magistrado Fernando Cruz y de la magistrada Ana Virginia Calzada, quiénes sí consideraban que había que dar curso a la acción - que el asunto debía ventilarse ante otra instancia judicial, al precisar la Corte que:
[...] no obstante, establecer si esa fundamentación es válida o no, si es contraria a la ciencia, técnica, lógica o conveniencia es una tarea que no compete a la jurisdicción constitucional, estimándose que se trata de aspectos propios de dilucidar ante la jurisdicción contencioso administrativa, a quien corresponde de conformidad con lo dispuesto en el artículo 49 de la Constitución Política, controlar la legalidad de la función administrativa del Estado (República de Costa Rica, Sala Constitucional de la Corte Suprema de Justicia, 2012).

Al observarse en tomas aéreas de medios de prensa nicaragüenses que la distancia entre el cauce del San Juan y el trazado de esta carretera paralela era mínimo, y al percatarse Nicaragua de que la ruta paralela al río San Juan se efectuó sin ningún tipo de estudios previos de impacto ambiental, Nicaragua presentó ante la CIJ una demanda contra Costa Rica el 22 de diciembre de 2011 por daños significativos provocados al río San Juan (República de Nicaragua, 2011). En relación a tomas aéreas, vale la pena indicar que, mientras los medios de prensa de Nicaragua publicaron tomas aéreas a partir de varios sobrevuelos desde noviembre de 2011, los medios de prensa de Costa Rica efectuaron sobrevuelos y publicaron las primeras tomas de la "trocha fronteriza" en marzo de 2012.

\section{La intención de Nicaragua al presentar su demanda}

Esta demanda presentada por Nicaragua el 21 de diciembre de 2011 en La Haya, un día después de hacerse pública la respuesta de la presidenta Chinchilla a un recurso planteado ante la Sala Constitucional contra la construcción de esta carretera paralela al San Juan por una fundación privada costarricense, no vino acompañada por ninguna solicitud de medidas provisionales a las que se recurre en situación de urgencia en La Haya. Por tanto, hay que buscar cuál puede ser la intención velada de Nicaragua al haberla presentado en los términos en los que la presentó 
oficialmente. Podemos intuir que, en realidad, esta demanda de Nicaragua viene a acompañar de una manera muy sutil la demanda inicial de Costa Rica contra Nicaragua por el dragado de 2010, con una clara intención: la de desacreditar ante la CIJ todos los argumentos esgrimidos por Costa Rica - en el caso del dragado - basados en consideraciones de tipo ambiental. Hemos tenido la oportunidad en un artículo de referirnos a este punto en particular:

La demanda presentada por Nicaragua persigue en parte el objetivo de debilitar ante los 15 jueces de La Haya todos los argumentos de tipo ambiental de Costa Rica presentados en relación con el dragado del San Juan y expuestos en un número anterior de esta misma revista (http://www. ambientico.una.ac.cr/209.pdf). Los requerimientos de estudios previos, la necesidad de informar al otro Estado ribereño del alcance de las obras, la evaluación del posible impacto transfronterizo de las obras previstas, la vulnerabilidad de la zona, las obligaciones internacionales en materia ambiental de un sinnúmero de convenios vigentes entre ambos Estados ribereños del San Juan, son argumentos que posiblemente presente ahora Nicaragua en relación con los 160 kilómetros de la carretera paralela al San Juan. De manera igualmente paralela, la tarea de minimizar el impacto ambiental de las obras realizadas, de denunciar una probable sobrevaloración de los daños ocasionados, o su carácter irreversible recaerá esta vez en Costa Rica. De ahí que se pueda esperar en los años venideros en La Haya un delicado ejercicio de paralelismo inverso por parte de ambas delegaciones, y del que los jueces en La Haya saquen posiblemente un único ganador: la protección del ambiente (Boeglin, 2012: 29).

Éste es justamente el sentido del párrafo 56 de la demanda de Nicaragua contra Costa Rica presentada el 21 de diciembre de 2011, al indicarle a la CIJ que Nicaragua "se reserva" la posibilidad de unir ambas demandas en una sola, al precisar:
Nicaragua is aware that the legal and factual grounds of the present case are connected to the ongoing case concerning Certain Activities carried out by Nicaragua in the Border Area (Costa Rica v. Nicaragua). Nicaragua reserves its rights to consider in a subsequent phase of the present proceedings and after further consideration of the other pending case whether to request that the proceedings in both cases should be joined.

No cabe duda de que, desde un punto de vista estrictamente jurídico, es un delicado y peligroso ejercicio de paralelismo inverso el que espera a los asesores legales de ambos países ribereños del río San Juan en los años venideros en La Haya, cuando ambas partes precisen sus argumentos ante los jueces de la CIJ.

\section{El grado de dificultad que conlleva para Costa Rica la demanda de Nicaragua}

Más allá de los cuestionamientos en relación con la improvisación y la falta de controles y de fiscalización, existen posibles actos de corrupción que investiga una comisión de la Asamblea Legislativa desde agosto de 2012, y que ha dado lugar a varias acciones por parte de la presidenta de Costa Rica, de la Fiscalía y de la Contraloría General de la República (CGR). Se inició la investigación mediante procesos administrativos de 21 altos funcionarios de Gobierno por parte de la CGR y el allanamiento por parte del Organismo de Investigación Judicial de seis empresas privadas ligadas a la construcción de esta ruta en diciembre de 2012 (Leandro, 2012).

La construcción de la denominada trocha fronteriza constituye también un reto para Costa Rica en el marco de sus controversias internacionales con Nicaragua. En primer lugar, se debe destacar que hemos asistido a un ejercicio raramente visto en relación con la terminología oficial usada para designar este proyecto considerado como prioritario por la actual administración de la presidenta Laura Chinchilla dado que lo que hoy se denomina trocha en Costa Rica no responde a la definición que da de este término el diccionario de 
la Real Academia Española, donde se define de la siguiente manera: "Trocha: 1. Vereda o camino angosto y excusado, o que sirve de atajo para ir a una parte. 2. Camino abierto en la maleza. 3. Ancho de las vías férreas."

Antes de calificarse de este modo, la obra fue denominada oficialmente como "camino", "carretera", "camino rústico" y "vía paralela" por las mismas autoridades de Costa Rica en distintos momentos. En el Decreto Ejecutivo de marzo de 2011 - publicado en el Alcance 14 de la Gaceta 46 del 7 de marzo de 2011-, se lee: “Artículo 8‥ Los predios de propiedad privada [...] deberán soportar todas las servidumbres legales necesarias para poder ejecutar las acciones, los procesos y las obras que realicen las entidades públicas."

Luego, el Ministerio de Ambiente utiliza la palabra "camino" en octubre de 2011. El propio ministro de Ambiente incluso titula "Camino rústico" un esclarecedor artículo sobre las motivaciones de este proyecto, publicado en La Nación en diciembre 2011. La misma presidenta de Costa Rica habla de un "camino que facilite el desplazamiento de nuestra policía, guarda parques y otras autoridades", de una "carretera paralela al río San Juan", y de una "vía paralela" el 20 de diciembre de 2011 en su respuesta al recurso de amparo presentado ante la Sala Constitucional de Costa Rica por parte de una fundación privada con fines sociales. El 23 de diciembre de ese mismo año, también la presidenta de Costa Rica habla de una "trocha fronteriza", mientras que la viceministra de Ambiente se refiere a un "camino paralelo" en enero de 2012. Finalmente, "ruta" es la palabra usada en la inauguración oficial del kilómetro cero realizada el 18 febrero de 2012. Esta inusitada creatividad gubernamental para designar las obras no se limita al ámbito oficial: una publicación de la Universidad Nacional titulada "El nuevo camino fronterizo" en la revista Ambientico de marzo de 2012 incluye una nota de presentación del editor, el cual habla de una "humilde carretera" en los términos siguientes: "La construcción apresurada de la humilde carretera fue la reacción natural del pacífico y huidizo Gobierno tico".
Pese a esteintenso esfuerzo en materia de vocabulario de unos y otros, se puede apreciar en la foto l que el aspecto rústico o humilde de esta vía, y el ancho que supone una trocha según la definición del diccionario de la Real Academia, son totalmente inexistentes (ver foto 1 ).

Más allá de estos problemas semánticos, que evidencian el grado de improvisación en la ejecución de este proyecto desde sus inicios, la falta de claridad sobre los objetivos que justifican este proyecto, y la preocupación de las autoridades por usar términos que no den argumentos a Nicaragua desde la perspectiva del impacto ambiental de dichas obras, existen otros elementos que tendrán implicaciones internacionales muy serias para Costa Rica. Por ejemplo, ante algunos cuestionamientos por parte de entidades ecologistas costarricenses en enero de 2012, las autoridades ambientales de Costa Rica precisaron en su respuesta, hecha pública en los medios, que:

Aunque se procuró mantener una distancia mínima de 50 metros de la ribera del río San Juan en los puntos en esta constituye línea de frontera, existen sitios a lo largo del camino en que tales distancias no se cumplieron [sic] (Guevara, 2012).

Esta última aseveración de la viceministra de Ambiente de Costa Rica resulta contradictoria con la gran cantidad de fotos y tomas aéreas que indican que la ruta paralela dista unos pocos metros del río San Juan, como la toma aérea que se reproduce en la foto 2. En el tramo que muestra la foto, y posiblemente en muchos otros más, no existe razón técnica que justifique una tan cercana aproximación al margen del río San Juan.

En la parte terrestre, en la que la frontera sigue puntos geodésicos fijados por los dos institutos geográficos nacionales, fotos incluidas en reportes de prensa muestran que las cuchillas de los tractores a cargo de la trocha rozaron mojones fronterizos. En un artículo publicado en un medio local, San Carlos al Día, se lee: "[...] fuimos testigos presenciales cómo la orden era que desde la trocha, se pudiera ver el río San 
Juan y en el límite artificial fuera rozando los mojones" (Quesada, 2012).

La prensa nicaragüense documentó este singular hecho (Silva, 2011), donde se indica claramente que los funcionarios públicos de Costa Rica y los empleados contratados para llevar a cabo las obras tenían la directriz de aproximarse lo más posible a la línea divisoria entre ambos estados.

En la inauguración del kilómetro cero realizada en febrero de 2012 en puesto Delta, la trocha fue oficialmente denominada por las autoridades de Costa Rica como Ruta Juan Rafael Mora Porras, en clara alusión a la histórica lucha emprendida por Costa Rica a mediados del siglo XIX contra los filibusteros provenientes de Estados Unidos y liderados por William Walker: una reafirmación del nacionalismo costarricense frente a Nicaragua y que no pasa fácilmente desapercibida para muchos observadores y analistas políticos de ambos países.

Adicionalmente, cabe indicar que, en las distintas justificaciones dadas en medios de prensa ante varios cuestionamientos, las autoridades de Costa Rica hacen referencia a los "miles de costarricenses que habitan en las riberas del río San Juan". No obstante, este tipo de aseveraciones dista sustancialmente de la cifra oficial aportada por la misma Costa Rica a la CIJ en el período 2005-2009 y que llevó a los jueces de La Haya a indicar en su decisión del 13 de julio de 2009 que el número de personas que vive del lado de Costa Rica a lo largo de los 140 kilómetros en los que el San Juan es frontera entre ambos países no llega a 500:

The Court considers it necessary to provide a factual context for the assessment which follows of the particular Nicaraguan regulations and actions challenged by Costa Rica. For this purpose, the Court recalls information presented to it about the population on the Costa Rican bank, the tourists using the river, and Costa Rican access to the area. According to Costa Rica, about 450 people, about half of them Nicaraguans, live along the approximately $140 \mathrm{~km}$ of the Costa Rican bank. Nicaragua does not challenge these figures (párrafo 98).
Esta diferencia entre el discurso oficial destinado a la opinión pública nacional y el dirigido a la opinión pública internacional se deja entrever de la misma manera en relación con los vocablos usados para calificar lo ocurrido en octubre de 2010 en Isla Portillos: mientras que las autoridades nacionales se refieren a ello como a una "invasión" o una "agresión" por parte de Nicaragua - términos usados en el mismo decreto de emergencia de marzo de 2011-, el Libroblanco editado por el Ministerio de Relaciones Exteriores de Costa Rica y destinado a informar a la comunidad internacional se titula: Incursión, ocupación, uso y daño del territorio costarricense por parte de Nicaragua (República de Costa Rica, Ministerio de Relaciones Exteriores, 2010).

Finalmente, es menester indicar que las obligaciones internacionales en materia ambiental que con tanto esmero Costa Rica invocó ante la CIJ en relación con el dragado ejecutado por Nicaragua, también son aplicables a Costa Rica para la construcción de 160 kilómetros de una ruta paralela al río San Juan. En un caso entre Argentina y Uruguay, la CIJ fue un poco más allá de su decisión de abril de 2010 al precisar el alcance de algunos principios generales, como por ejemplo el considerar como una regla de carácter consuetudinario la obligación para el Estado de: "[...] recurrir a todos los medios a su disposición para evitar que las actividades que se desarrollan en su territorio o sobre todo espacio sometido a su jurisdicción causen un daño sensible al ambiente de otro Estado" (párrafo 101).

Adicionalmente, la CIJ consagró como una obligación de carácter consuetudinario -y no sólo convencional, lo cual constituye un precedente de peso- el proceder a una evaluación del impacto ambiental cuando un proyecto es susceptible de provocar un daño importante de tipo transfronterizo.

La diligencia debida, y el deber de vigilancia y de prevención que implica, podría considerarse que no fue ejercida, si una parte que proyecta obras susceptibles de afectar el régimen del río o la calidad de sus aguas no realizó un estudio de impacto ambiental de los efectos potenciales de las obras previstas (CIJ, 2010, párrafo 204). 
Como se puede apreciar, la construcción de esta ruta paralela al río San Juan constituye para Costa Rica un verdadero desafío en su contienda con Nicaragua en La Haya en relación con el dragado. Por su parte, Nicaragua ha demostrado en el pasado en La Haya contra Estados Unidos -fallo de 1984 sobre excepciones preliminares y de 1986 sobre el fondo - o contra Colombia - fallo reciente de noviembre de 2012 - que sabe capitalizar los errores de sus contrincantes y sacarles el mayor provecho para confirmar sus pretensiones.

\section{Una obra sin precedentes en América Latina}

Cabe finalmente indicar que, con esta ruta paralela a la frontera con Nicaragua, Costa Rica opta en casi toda su extensión por una solución que únicamente países altamente militarizados, y en situaciones muy particulares, han llevado adelante. La literatura especializada sobre fronteras no se ha interesado mayormente por sistematizar información sobre las fronteras que son acompañadas por un cordón vehicular en prácticamente toda su extensión, ubicado éste en uno de los dos lados del trazado de la línea divisoria. Las únicas referencias registradas son el caso de la frontera entre las dos Coreas, de 238 kilómetros de longitud, y el caso de las fronteras de Israel con Egipto, Siria y Jordania. Este mismo diseño se encuentra en el caso de fronteras "muro", tipo muro de Israel, en territorios cisjordanos - cordón vehicular paralelo para unidades del ejército israelí-, o en el caso del Muro de Berlín. En América Latina no se tiene referencia de una sola frontera internacional que haya dado lugar a semejante decisión política. La única que de manera muy parcial se aproxima a este diseño es la frontera entre Estados Unidos y México en algunos de sus sectores - California, Arizona y Nuevo México en la región de El Paso, y Texas- y que cuenta con una extensión de 3326 kilómetros. En este tramo existe del lado norteamericano, o se proyecta construir, una ruta paralela a la línea divisoria, la cual, en particular en la región de El Paso, se extiende varios cientos de kilómetros por el desierto — ruta paralela a la línea divisoria del lado de Estados Unidos para el uso de sus unidades de patrullaje y vigilancia-.
Es de notar que, en una zona tropical como la que separa Costa Rica de Nicaragua, una obra tal conlleva necesariamente la toma en consideración de factores inexistentes en zonas semidesérticas: uno de ellos es el alto costo de mantenimiento debido a los rigores del clima tropical y a los caprichos del mismo río San Juan. Reportes de prensa indicaron que el 17 de diciembre de 2011 el San Juan inundó la zona de Delta Costa Rica, abarcando una zona distante de su cauce más de 200 metros del lado costarricense (Hernández, 2011).

\section{Conclusión}

Resulta evidente para el observador que en estos últimos años Costa Rica y Nicaragua se han enfrascado en complejos procesos judiciales ante la CIJ por falta de capacidad de diálogo y negociación entre ambos para resolver bilateralmente sus disputas, dando lugar a un "espectáculo vergonzoso" según el politólogo costarricense Alberto Cortés Ramos (Ramírez, 2011). El hecho de que desde mayo de 2010 Costa Rica no tuviera embajador en Managua - el cual fue juramentado tan solo en agosto de 2012 y tomó posesión del cargo en septiembre de 2012permite evidenciar la falta de canales diplomáticos adecuados entre estos dos Estados, lo que hubiese tal vez permitido a Costa Rica anticipar el curso de los acontecimientos a partir de los meses de agosto y septiembre de 2010. La reacción de Costa Rica y el uso de calificativos como "agresión" o "invasión" por parte de las autoridades para referirse a la presencia en su suelo de unos 20 soldados de Nicaragua para custodiar la construcción de un caño artificial en una remota zona fronteriza (Boeglin, 2012) propició en parte este desenlace. Si bien podemos entender la intención de la Corte Internacional de Justicia en su decisión del 8 de marzo de 2011 de obligar a los Estados a restablecer paulatina y gradualmente los canales oficiales en pro de mejorar sus ya deterioradas relaciones, esta intención del juez internacional pareciera haber sido ignorada, colocando a ambos países en una situación de confrontación verbal y de 
tensión extrema. La denominada "trocha paralela" o "ruta Juan Rafael Mora Porras" es considerada por algunos como una aguda expresión de nacionalismo costarricense exacerbado y que, curiosamente, amenaza desde el punto de vista político a la actual administración —en razón del mal manejo de los fondos públicos y de actos de corrupción investigados por la Asamblea Legislativa, el Ministerio Público, la Contraloría General de la República y, en parte, por la misma prensa costarricense- De alguna manera, la trocha fronteriza es el resultado de una actitud muy peculiar asumida por las autoridades actuales de Costa Rica: el considerar la frontera norte como un verdadero frente y no como una zona de cooperación y de intercambio. Esta trocha conduce inevitablemente a acentuar en el terreno el efecto divisorio del trazado de la línea fronteriza, en detrimento de los tradicionales lazos familiares, comerciales y culturales que han forjado desde hace muchos años las poblaciones ribereñas del río San Juan. Éstas, por lo demás, comparten una misma realidad: la de vivir en los departamentos o cantones más abandonados por sus respectivas capitales -y que reflejan de manera llamativa los índices sobre desarrollo humano a nivel cantonal en Costa RicaPosiblemente, para muchas comunidades ribereñas la prioridad en materia de infraestructura vial en esa zona era reparar caminos para acceder de mejor manera a la red vial, en un eje norte-sur o hacia los centros de actividad comercial y los mercados ubicados en Ciudad Quesada, pero posiblemente nunca visualizaron que fuera prioritaria una ruta paralela al río y a la línea divisoria en la parte terrestre que siguiera el río San Juan en cada una de sus convulsas y múltiples circunvoluciones. Podemos concluir con Carlos Sandoval García indicando que: "En términos de los esfuerzos de organizaciones de la sociedad civil, orientadas a fortalecer políticas de interculturalidad, el conflicto fronterizo significa un gran retroceso" (Sandoval, 2012: 189). Y adelantar que posiblemente correrá mucha agua por el cauce del San Juan antes de que se logren poco a poco normalizar las relaciones entre Costa Rica y Nicaragua.

\section{Bibliografía}

Alfaro M., Ximena (2011), "Desconfianza y caos marcan cita con nicas en frontera norte", en La Nación, 13 de abril, Costa Rica. 〈http://www.nacion.com/2011-0413/ElPais/NotasSecundarias/ElPais274686l.aspx> [7 de marzo de 2013].

Araya, Jorge Luis (2012), "Se mantiene interrogante de quién ordenó construir la trocha fronteriza", en Semanario Universidad, 22 de agosto, Costa Rica. 〈http://www.semanario.ucr.ac.cr/index.php/ noticias/pais/6816-se-mantiene-interrogante-dequien-ordeno-construir-trocha-fronteriza.html> [13 de enero de 2012].

Astorga, Allan (2010a), "Dragado del río San Juan: sí habrá impactos ambientales", en Diario Extra, 21 de septiembre, Costa Rica. 〈http://www. diarioextra.com/2010/setiembre/21/opinionll. php> [14 de diciembre de 2012].

Astorga, Allan (2010b), "Dragado del río San Juan", en La Nación, 13 de noviembre, Costa Rica. 〈http://www.nacion.com/2010-11-14/Opinion/ Foro/Opinion2588598.aspx> [14 de diciembre de 2012].

Boeglin Naumovic, Nicolás (2010), "Dragado del Río San Juan: impacto transfronterizo y consistencia jurídica”, en El Pais.cr, 8 de septiembre, Costa Rica. 〈http://www.elpais.cr/articulos.php?id=31749〉 [14 de diciembre de 2012].

Boeglin Naumovic, Nicolás (2011), "Dragado del río San Juan y balance en la decisión de La Haya del 8 de marzo entre Costa Rica y Nicaragua: perspectiva histórica, política y legal", en Revista Estudios, núm. 24. <http://www.estudiosgenerales.ucr.ac.cr/estudios/ no24/papers/vsec3.html> [17 de diciembre de 2012].

Boeglin Naumovic, Nicolás (2012), "Alcances de la demanda en La Haya de Nicaragua contra Costa Rica en relación con la de Costa Rica contra Nicaragua referente al dragado: iejercicio de paralelismo inverso?", en Ambientico. Revista Mensual sobre la Actualidad Ambiental, núm. 22l, marzo, pp. 26-30. 〈http://www.ambientico. una.ac.cr/pdfs/ambientico/22l.pdf> [14 de diciembre de 2012]. 
Corte Internacional de Justicia (2010), Pulp Mills on the River Uruguay (Argentina v. Uruguay), Judgment, I.C.J., núm 977, 20 de abril. 〈http://www.icj-cij.org/docket/ files/135/15877.pdf> [14 de diciembre de 2012].

Guevara, Lorena (viceministra de Ambiente) (2012), Plan Preliminar de Mitigación y/o Compensación Ambiental de la Zona Impactada por la Construcción del Camino paralelo al Río San Juan, Oficio DVM-002-2012, 2 de enero, Costa Rica: Ministerio de Ambiente, Energía y Mares [inédito].

Hernández P., Carlos (2011), "Lluvia dañó carretera paralela al río San Juan”, en La Nación, 17 de diciembre, Costa Rica. 〈http://www.nacion.com/2011-12-17/ ElPais/lluvia-dano--carretera-paralela-al-rio-sanjuan.aspx> [14 de diciembre de 2012].

Quesada, Gustavo (2012), "La trocha fronteriza y la hipocresía", en San Carlos al Día, 15 de junio. 〈http:// www.sancarlosaldia.com/noticias/editorial/latrocha-fronteriza-y-la-hipocresia.html $\quad[14$ de diciembre de 2012].

Leandro, Marco (2012) "Allanan 6 empresas de la trocha", en Diario Extra, ll de diciembre, Costa Rica. 〈http://www.diarioextra.com/2012/diciembre/1l/ nacionalesl0.php> [14 de diciembre de 2012].

Mata, Esteban A. (2010), "Google acepta error en mapa entre Costa Rica y Nicaragua”, en La Nación, 5 de noviembre, Costa Rica. 〈http://www.nacion. com/2010-11-05/ElPais/UltimaHora/ElPais2580654. aspx> [14 de diciembre de 2012].

Ramírez, Ernesto (2012), "Vecinos del río San Juan claman por oportunidades y piden desterrar diferencias", en Semanario Universidad, 1 de febrero. 〈http://semanario. ucr.ac.cr/index.php/noticias/pais/5172-vecinos-del- rio-san-juan-claman-por-oportunidades-y-pidendesterrar-diferencias-html> [14 de diciembre de 2012].

República de Costa Rica, Ministerio de Relaciones Exteriores (2010), Incursión, ocupación, uso y daño del territorio costarricense por parte de Nicaragua, San José, noviembre 2010 [ibro blanco], Costa Rica: el Ministerio.

República de Costa Rica, Sala Constitucional de la Corte Suprema de Justicia (2012), Exp: 12-007663-0007-CO, Res. № 2012008420, 22 de junio [inédito].

República de Nicaragua (2011), Application of the Republic of Nicaragua instituting proceedings against the Republic of Costa Rica to the registrar International Court of Justice, 21 de diciembre. 〈http:/www.icj-cij.org/docket/ files/152/16917.pdf > [14 de diciembre de 2012].

Sandoval García, Carlos (2012), "De Calero a la Trocha: la nueva disputa entre los Gobiernos de Costa Rica y de Nicaragua (2010-2012)", en Anuario de Estudios Centroamericanos, vol. 38, pp. 179-192.

Silva, José Adán (2011), “Trocha Tica 'aruña' territorio nacional", en El Nuevo Diario, 12 de noviembre, Nicaragua. 〈http://www.elnuevodiario.com.ni/ nacionales/233030> [14 de diciembre de 2012].

Tijerino Pacheco, José María (2013), "Dos graves inexactitudes", en La Nación, 31 de enero, Costa Rica. 〈http://www.nacion.com/2013-01-31/Opinion/Dosgraves-inexactitudes.aspx> [15 de febrero de 2013].

Walker, Peter (2010), "Nicaragua to keep troops in disputed territory after Google Maps error", en The Guardian, 11 de noviembre, Reino Unido. 〈http:// www.guardian.co.uk/world/2010/nov/1l/nicaraguatroops-calero-island-google-maps> [14 de diciembre de 2012]. 


\section{Mapa 1}

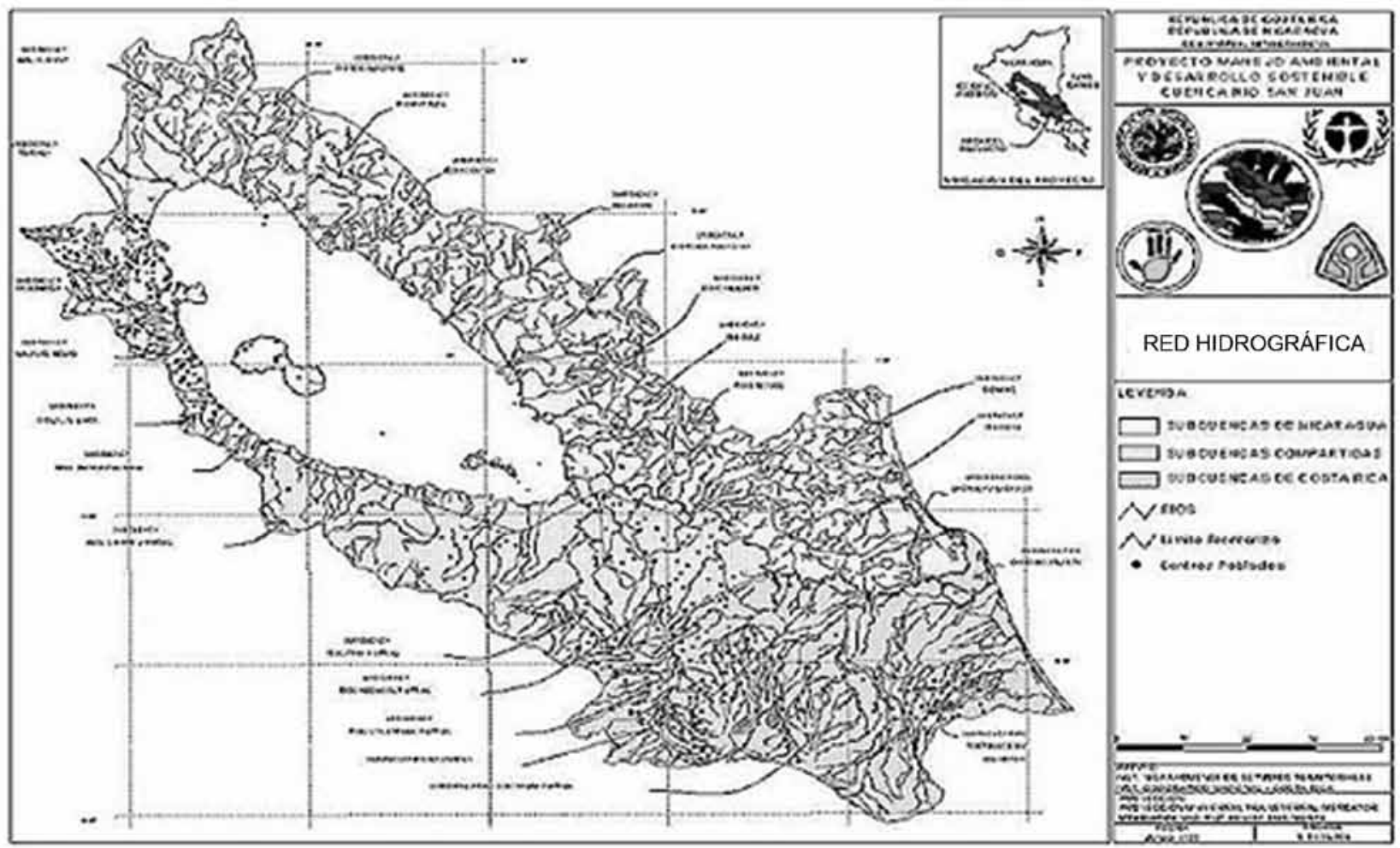

Mapa elaborado en el marco del Proyecto Pro Cuenca Río San Juan, OEA, entre 1993 y 1996, con el apoyo del Ministerio de Ambiente, Energía y Mares de Costa Rica y del Ministerio del Ambiente y los Recursos Naturales de Nicaragua. Ver sitio oficial: 〈http://www.oas.org/sanjuan/defaultesp.html〉 [7 de marzo del 2013]. 
Mapa 2.

Mapa de la desembocadura del río San Juan, incluida la laguna de Portillos en el extremo norte

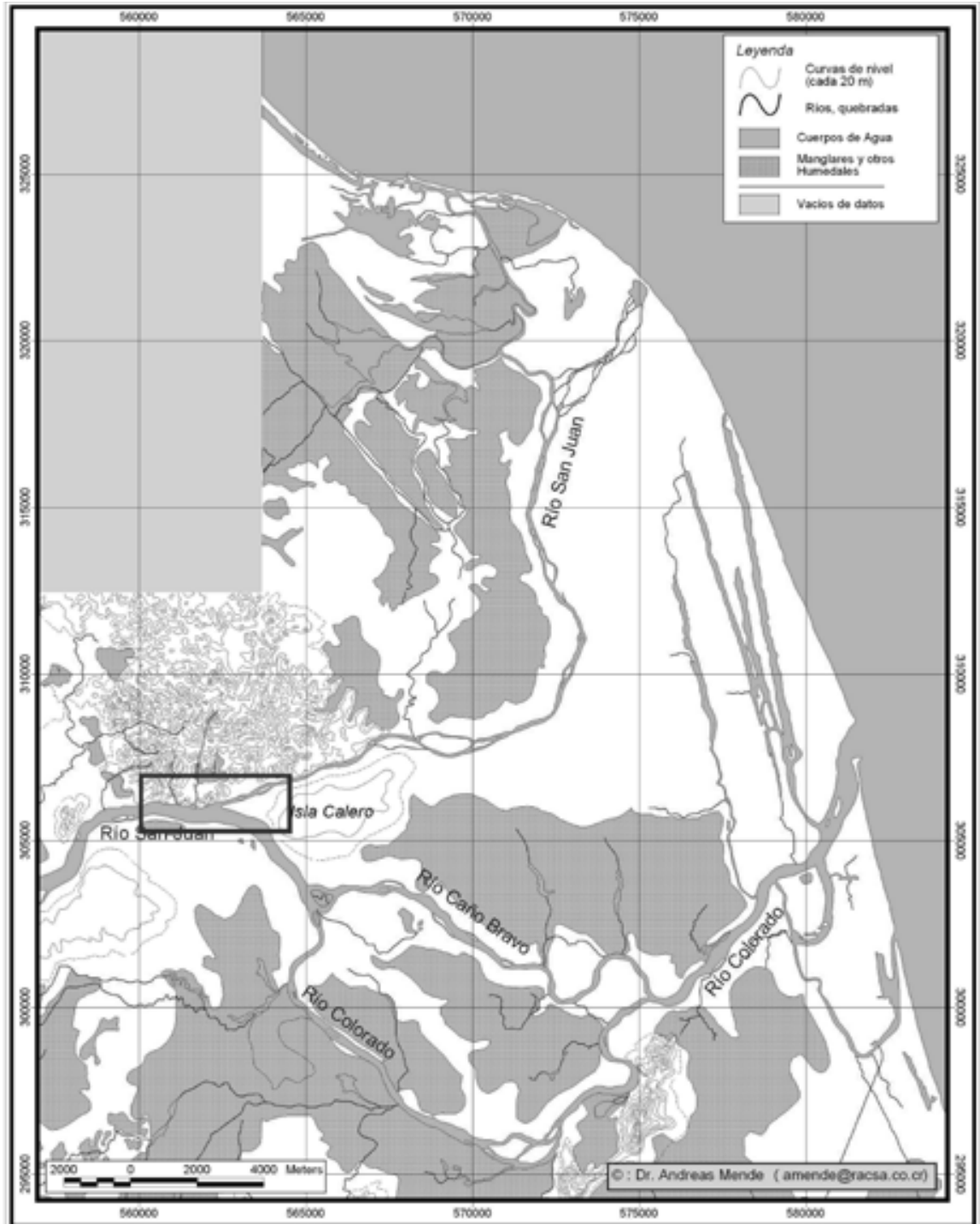

Fuente: Dr. Allan Astorga Gattgens, profesor en la Escuela Centroamericana de Geología de la Universidad de Costa Rica. 
Mapa 3

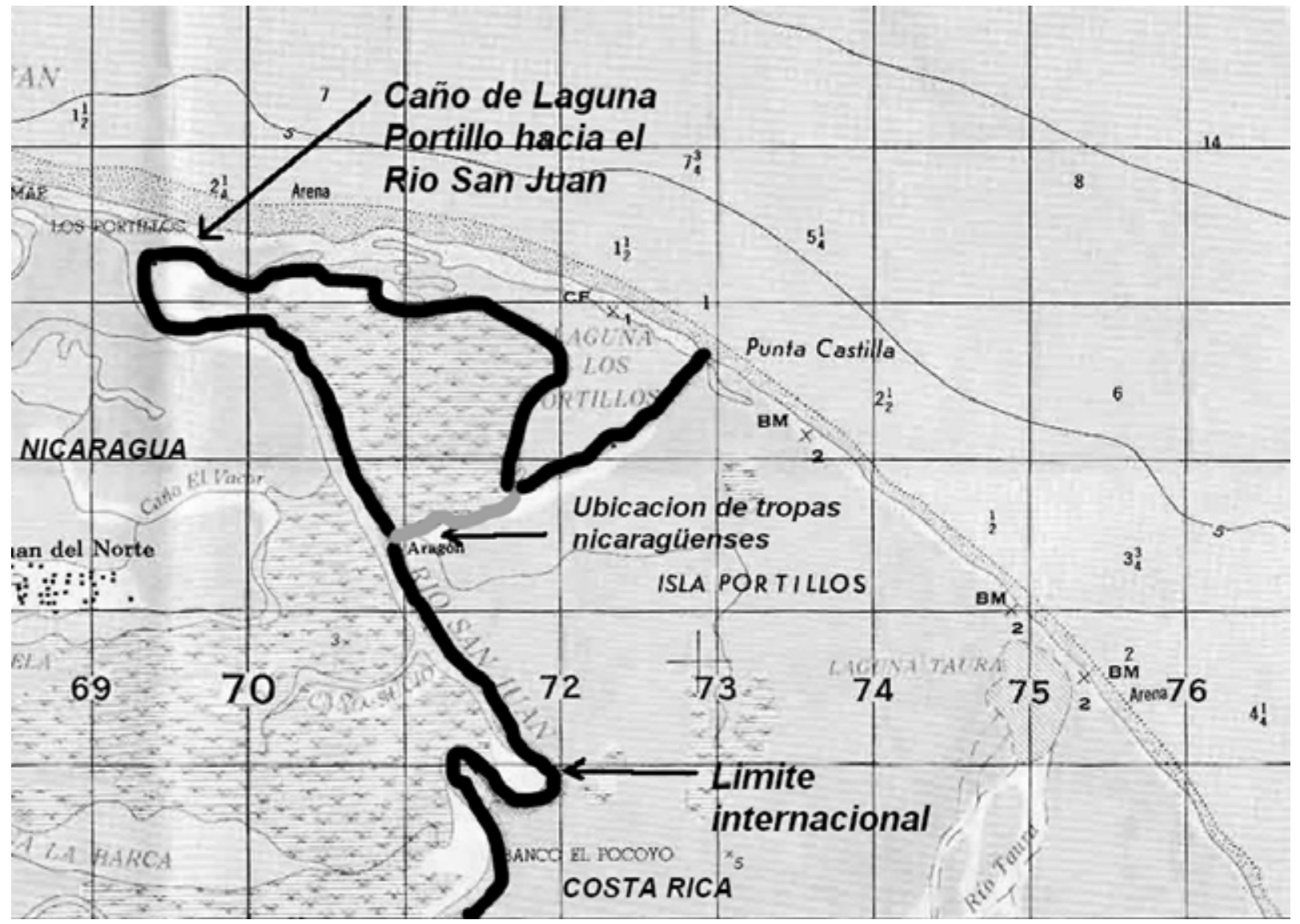

En negro, el trazado de la frontera usualmente reportado en mapas de Costa Rica y Nicaragua desde 1897 en sus respectivos mapas oficiales. En gris, la ubicación del caño Pastora realizado por Nicaragua a partir de octubre de 2010.

Fuente: Dr. Allan Astorga Gattgens, profesorde la Escuela Centroamericana de Geología de la Universidad de Costa Rica. 


\section{Foto 1}

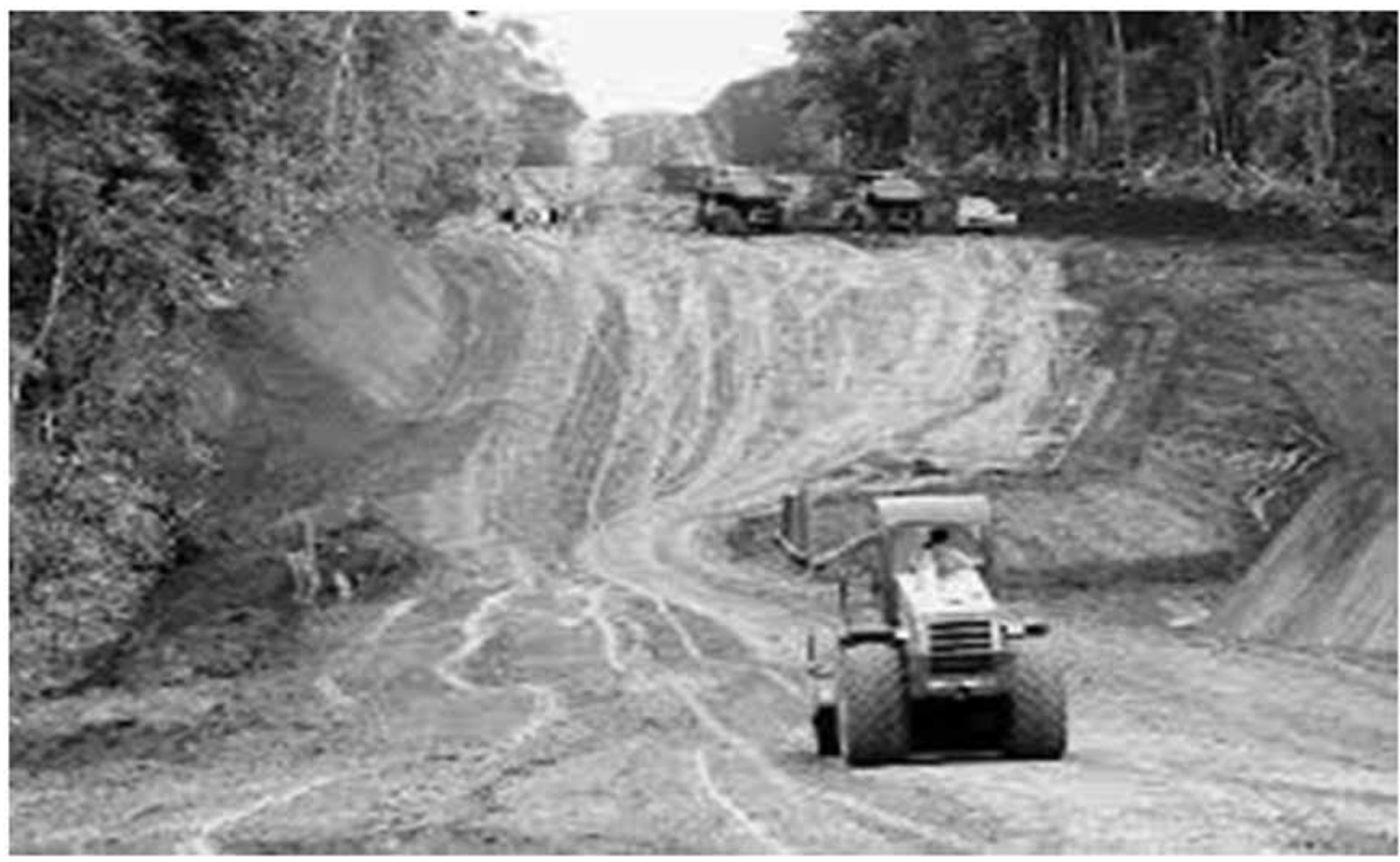

Fuente: Foto de portada de la revista Ambientico. Revista Mensual sobre la Actualidad Ambiental, núm. 221, marzo de 2012. 〈http://www.ambientico.una.ac.cr/pdfs/ambientico/221.pdf〉 [7 de marzo de 2013]. 
Foto 2

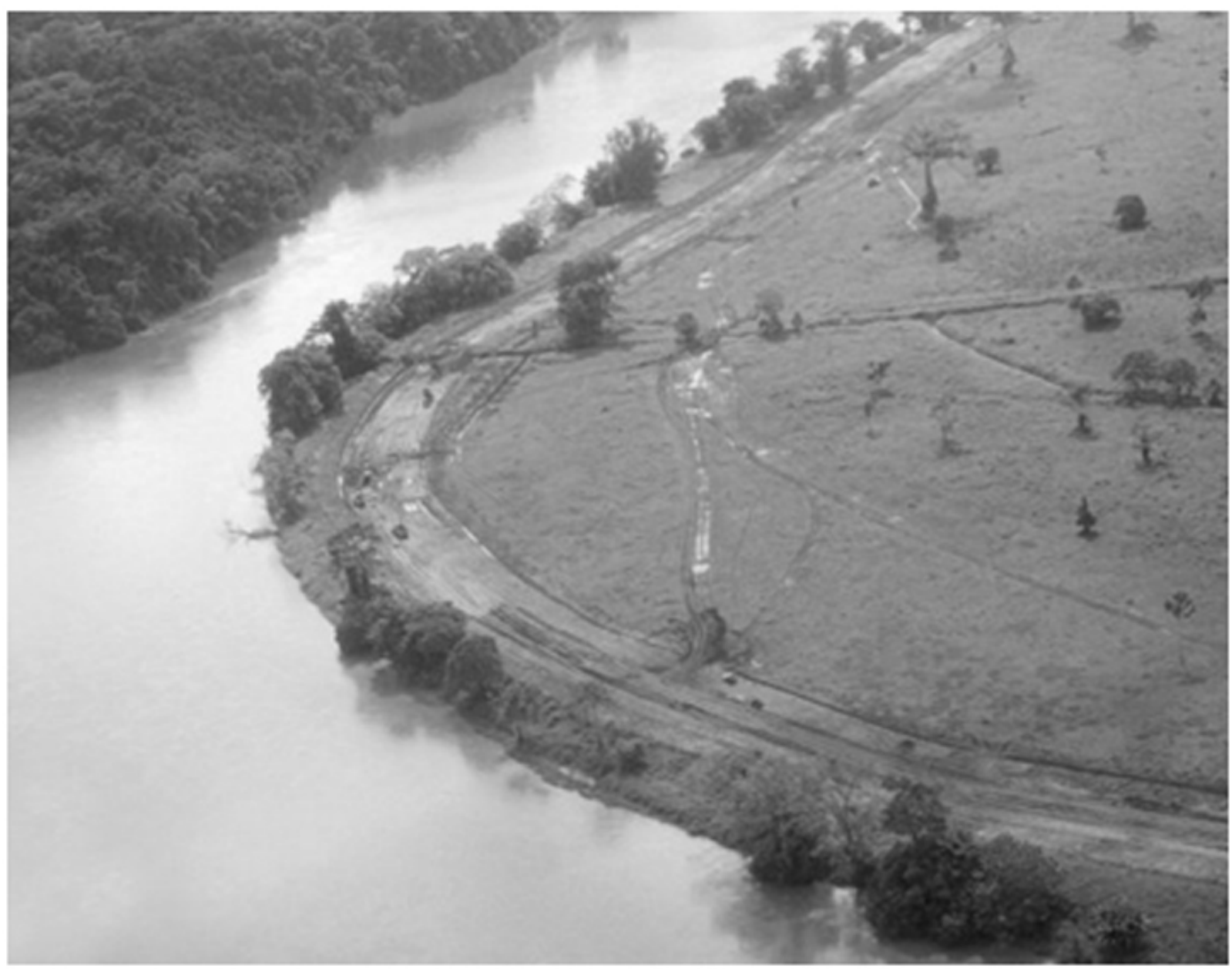

Fuente: archivo Elpais.cr. en: 〈http://www.elpais.cr/frontend/noticia_detalle/1/63675〉 [7 de marzo del 2013]. 